\title{
CODE PROVISIONS FOR CONFINING STEEL IN POTENTIAL PLASTIC HINGE REGIONS OF COLUMNS IN SEISMIC DESIGN
}

\author{
R. Park* and M.J.N. Priestley*
}

\section{ABSTRACT}

A summary is given of the provisions for both circular and rectangular confining steel in potential plastic hinge zones of columns, as specified in the seismic codes of various countries. In particular, a comparison is made between New Zealand and overseas recommendations. The background to the confining steel provisions recommended in the draft SANZ Concrete Design Code is outlined.

\section{INTRODUCTION}

Energy dissipation provided by the development of ductile plastic hinges in columns is essential to the satisfactory response under seismic loading of many structures. In particular, a large proportion of modern bridge structures constructed in zones of high seismic activity are supported by piers consisting of one or more columns. Inelastic response of these bridge structures under seismic attack will invariably involve plastic hinging of the columns, unless mechanical energy dissipators are incorporated in the design. Although current seismic design philosophy for multistorey reinforced concrete framed buildings, as specified by the SANZ Loadings Code $(1)$ is directed towards ensuring the formation of plastic hinges in the beams rather than in the columns, it is necessary to develop plastic hinges at the base of the columns to obtain a full plastic mechanism. Also, for one or two storey frames, and for the top storey of multistorey frames, plastic hinging in columns leading to column sidesway mechanisms ${ }_{1}$ is permitted by the SANZ Loadings Code $(1)^{\text {s }}$.

It is now widely accepted that adequate ductility of column plastic hinges can only be obtained if sufficient transverse confining reinforcement is provided to confine the concrete core of the column, to prevent lateral buckling of the longitudinal flexural reinforcement, and to provide adequate shear reinforcement. During the San Fernando earthquake of February 9, 1971 failure of the columns of several bridges and buildings could be directly attributed to inadequate confinement of the plastic hinge regions. Nevertheless, the amount and distribution of confining reinforcement necessary to ensure adequate ductility without significant strength degradation is still a matter of some controversy. Very significant differences exist between the provisions for confining steel specified in the seismic codes of various countries.

This paper summarises the present recommendations made for both circular and

* Department of Civil Engineering, University of Canterbury. rectangular confining steel in commonly used seismic codes and makes a comparison between New Zealand and overseas recommendations.

\section{THE CODES CONSIDERED}

The overseas codes for reinforced concrete design best known to New Zealanders are probably the ACI Building Code(3), the SEAOC Code (4), and the teptative provisions for buildings of the ATC $(5)$. In addition there is available an ACI Committee 343 report on the analysis and design of bridge structures (6), and the California Department of Transportation has design rules(7). An indication of current Japanese practice can be obtained from publications in English, for example $(8,9)$. In New Zealand, the Ministry of Works and Development have developed provisions for confinement of bridge piers (10, 11); also, the Standards Association of New Zealand has prepared a draft Concrete Design Code (12), which has been available for comment during 1978 and is now being redrafted into its final form in the light of comments received.

The summary given in the following sections includes the provisions for confining steel of both circular and rectangular shape. This summary will not include references to design for shear reinforcement, it being understood that the transverse steel placed for confinement will also act as shear reinforcement, and that there may be cases where further transverse steel is necessary to provide adequate shear strength.

Generally the quantity of circular confining steel is expressed in terms of $\rho_{s}$, which is the volumetric ratio of spiral or' circular hoop reinforcement confining the concrete core.

$$
\rho_{s}=\frac{{ }_{s p} \pi d_{s}}{s_{h} \pi\left(d_{s} / 2\right)^{2}}=\frac{4 A_{s p}}{d_{s} s_{h}}
$$

For confining steel of rectangular shape, with or without supplementary cross ties, the quantity of transverse steel is expressed by $A_{\text {sh }}$ which is the total area 
of hoop bars and supplementary cross ties in the direction under consideration within longitudinal spacing $s_{1}$. Sometimes (10) $\rho$ is used to define the total volumetric ratio of rectangular hoops plus supplementary cross ties in the section confining the concrete core.

ACI $318-77^{(3)}$

Confining steel consisting of spiral or hoop reinforcement is required over the end regions of columns adjacent to moment resisting connections over a length from the face of the connection equal to the greater of the overall thickness $h$ (h being the larger sectional dimension for rectangular columns or the diameter for circular columns), one-sixth of the clear height of the column, or $457 \mathrm{~mm}$ (18 in).

For spiral reinforcement, if $\mathrm{P}_{e}<\phi 0.4 \mathrm{P}_{\mathrm{b}^{\prime}} \rho_{\mathrm{s}}$ is required to be at least equal to

$$
\rho_{s}=0.45\left(\frac{A_{g}}{A_{C}}-1\right) \frac{f_{C}^{\prime}}{f_{y h}} .
$$

If $\mathrm{P}_{\mathrm{e}}>0.4 \phi \mathrm{P}_{\mathrm{b}}, \rho_{\mathrm{s}}$ should not be less than that given by Eq. 2, or

$$
\rho_{\mathrm{S}}=0.12 \mathrm{f}_{\mathrm{C}}^{\prime} / \mathrm{f}_{\mathrm{yh}}
$$

whichever is greater. In both cases, the spiral bar diameter should not be less than $9.5 \mathrm{~mm}\left(\frac{3}{8}\right.$ in), and the clear spacing between spirals should not exceed $76 \mathrm{~mm}$ (3 in) nor be less than $25 \mathrm{~mm}$ ( 1 in).

For rectangular hoop reinforcement, with or without supplementary cross ties, if $\mathrm{P}_{e}<\phi 0.4 \mathrm{P}_{\mathrm{B}}$, the transverse steel should be designed as for beams but the hoop bar djameter should not be less than $9.5 \mathrm{~mm}$ $\left(\frac{3}{2}\right.$ in) and the spacing should not exceed d92. If $\mathrm{P}>\phi 0.4 \mathrm{P}$, and a single rectangular hoop is used, the area of one leg of the hoop bar in the direction considered within spacing $\mathrm{s}_{\mathrm{h}}$ should be at least equal to

$$
\mathrm{A}_{\mathrm{sb}}=I_{\mathrm{h}} \mathrm{s}_{\mathrm{h}} / 2
$$

where $\rho_{s}$ is as calculated by the greater of Eqs. ${ }^{2} 2$ and 3 with $A$ taken as the area of concrete core measured to the outside of the peripheral hoop. The value of $\mathrm{s}_{h}$ used should not exceed $102 \mathrm{~mm}$ (4 in).

Supplementary cross ties of the same bar diameter as the hoop may be used to reduce the unsupported length $l_{1}$. The hoop and cross tie bar diameter should not be less than $9.5 \mathrm{~mm}$ ( $\frac{3}{8}$ in) for longitudinal bars $31.8 \mathrm{~mm} \mathrm{(1 \frac {1 } { 4 }}$ in) diameter or smaller, or $12.7 \mathrm{~mm}\left(\frac{1}{2}^{4}\right.$ in) for larger longitudinal bars or bundled bars.

SEAOC (1975) (4)

The potential plastic hinge zone is taken as in ACI 318-77.

For spiral reinforcement, $\rho$ is taken as the greater of Eqs. 2 or 3 regardless of the axial load level and detailing is as in ACI 318-77.

For rectangular hoop reinforcement the total area of hoop bar and supplementary cross ties (if any) in the direction under consideration within spacing $s_{h}$ should not be less than

$$
A_{s h}=0.3 s_{h} h^{\prime \prime} \frac{f_{C}^{\prime}}{f_{y h}}\left(\frac{A_{g}}{A_{C}}-1\right)
$$

or

$$
A_{s h}=0.12 s_{h} h^{\prime \prime} f_{c}^{\prime} / f_{y h}
$$

whichever is greater. The value of $\mathrm{s}_{\mathrm{h}}$ used should not exceed $102 \mathrm{~mm}$ (4 in), and supplementary cross ties or legs of overlapping hoops should not be spaced at more than $356 \mathrm{~mm}$ (14 in) between centres transversely.

ATC (1978) (5)

The SEAOC provisions appear to have been followed for fully ductile frames.

ACI COMMITTEE $343^{(6)}$

For spiral steel $\mathrm{Eq} .2$ is specified up the whole height of the column without any limit on axial load level. There is no mention of Eq. 3. Spacing and spiral bar size requirements are as in ACI 318-77.

For rectangular hoop steel the transverse bar diameter is specified as in ACI 318-77. THe quantity of transverse steel is not specified, but it is stated that the tie spacing should not exceed the lease dimension of the member or $305 \mathrm{~mm}$ (12 in), except that when bars larger than $31.8 \mathrm{~mm}$ ( $1 \frac{1}{4}$ in) diameter are bundled the tie spacing should be reduced to one-half of that value.

\section{CALTRANS}

It is understood (7) that the current practice of the California Department of Transportation involves for circular columns the use of $12.7 \mathrm{~mm}$ ( $\frac{1}{2}$ in) diameter spirals at $89 \mathrm{~mm}$ ( $3 \frac{1}{2}$ in) centres from steel with a value for $f_{\text {of }}$ at least $414 \mathrm{MPa}$ $(60,000 p s i)$. $\mathrm{yh}_{\mathrm{These}}$ provisions apply regardless of column diameter or axial load level.

\section{JAPANESE PRACTICE}

No information was available to the authors regarding current Japanese practice for bridges. However, available literature indicates confining ratios are substantially less than ACI 318-77 requirements, and spiral contents for bridges are often as low as $\rho=0.001$. AIJ requirements for buildings (9) specify a minimum rectangular hoop diameter of $9 \mathrm{~mm}(0.35 \mathrm{in})$ with spacing 
not to exceed the lesser of $150 \mathrm{~mm}$ ( $5.9 \mathrm{in}$ ), one-half of the smaller column dimension, or 7.5 longitudinal bar diameters.

N.Z. MINISTRY OF WORKS AND DEVELOPMENT, CIVIL DIVISION $(10,11)$

Until recently the design of confining reinforcement for bridge columns was governed by the MWD provisions $(10,11)$ This involves providing sufficient confining steel to ensure that the available structure displacement ductility factor $\mu$ is at

least 6 , based on the following steps:

1. The ratio of the structure displacement ductility factor, $\mu$, to curvature ductility factor, $\phi / \phi$, within the plastic hinge region is calculated. The ratio depends on geometric considerations, and the plastic hinge length which is taken to be that given by Baker's formula(13).

2. Calculate the yield curvature $\phi_{y}$, and hence the required ultimate curbature $\phi_{\mathrm{u}} \cdot$

3. Calculate the "ultimate" compression strain $\varepsilon_{\text {cu }}$ corresponding to $\phi_{1}$, based on a conservative idealisation for the stress-strain curve of confined concrete.

4. Calculate the required volumetric ratio of confining reinforcement. For spiral or circular hoop steel $\rho_{s}$ is obtained using

$$
\varepsilon_{c u}=0.0033\left\{0.29+150 p_{s}+\left(0.7-10 p_{s}\right) \frac{d}{c}\right\}
$$

For rectangular hoops and supplementary cross ties $\rho_{\mathrm{s}}$ is obtained using

$\varepsilon_{\mathrm{cu}}=0.0021\left\{1+150 \rho_{\mathrm{s}}+\left(0.7-10 \rho_{\mathrm{s}}\right) \frac{\mathrm{d}}{\mathrm{c}}\right\}$ Eqs. 7 and 8 are based on the work of Baker made significantly less conservative than the results of that work in the light of the findings of more recent tests (see the December 1977 amendment(10), .

It is understood that the MWD will be adopting the requirements of the new SANZ Concrete Design Code (at present in draft form(12)) when that SANZ code is available in its final form.

DRAFT SANZ CONCRETE DESIGN CODE (11)

The confinement provisions of the draft SANZ Concrete Design Code, DZ3101, are based on the ACI/SEAOC requirements modified to take account of the effect of axial load level.

\section{(a) First Draft}

In the first draft of DZ3101, issued for comment in 1978 , the potential plastic hinge regions were specified as in ACI 318-77.
The volumetric ratio for spiral or circular hoop reinforcement in potential plastic hinge regions, when $P_{e}<0.7 f_{C}^{\prime} A^{\prime}{ }^{\prime}$ was required to be not less than

$$
\rho_{s}=0.45\left(\frac{A_{g}}{A_{C}}-1\right)^{f_{C}^{\prime}} \frac{f_{Y h}}{f_{y h}}\left(0.375+1.25 \frac{P_{e}}{f_{C}^{\prime} A_{g}}\right.
$$

nor

$\rho_{\mathrm{s}}=0.12 \frac{\mathrm{f}_{\mathrm{C}}^{\prime}}{\mathrm{f}_{\mathrm{Yh}}}\left(0.375+1.25 \frac{\mathrm{P}_{\mathrm{e}}}{\mathrm{f}_{\mathrm{C}}^{\prime} \mathrm{A}_{\mathrm{g}}}\right)$

where $P$ was not to be taken as less than $0.1 f^{\prime}{ }^{A}$. The diameter of spiral or circular hoop bar was to be at least $10 \mathrm{~mm}$ (0.39 in) and the maximum centre to centre spacing of spirals or circular hoops was not to exceed the smaller of one-fifth of the member diameter, $125 \mathrm{~mm}$ (4.9 in), or six times the diameter of the longitudinal bars.

The total area of rectangular hoop reinforcement, including supplementary cross ties if any, in the direction under consideration in potential plastic hinge regions, when $\mathrm{P}_{\mathrm{e}}<0.6 \mathrm{f}_{\mathrm{C}}^{\prime} \mathrm{A}_{\mathrm{g}}$, was required to be not less than

$A_{s h}=0.3 s_{h} h^{\prime \prime}\left(\frac{A_{g}}{A_{C}}-1\right) \frac{f_{C}^{\prime}}{\bar{F}_{y}}\left(0.33+1.67 \frac{P_{e}}{f_{C}^{\prime} A_{g}}\right)$

nor

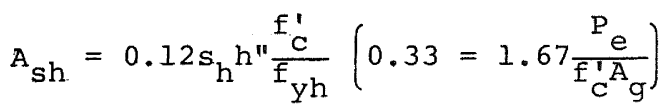

where $\mathrm{P}_{\mathrm{e}}$ was not to be taken as less than $0.1 f^{\prime} A^{*}$. The diameter of hoop or tie bar was to be at least $10 \mathrm{~mm}$ (0.39 in), and the maximum centre to centre spacing of hoop sets was not to exceed the smaller of one-fifth of the smaller member section dimension, $150 \mathrm{~mm}(5.9 \mathrm{in})$, or six times the diameter of the longitudinal bars. The yield force of the hoop bar or supplementary cross tie was to be at least one-sixteenth of the yield force of the longitudinal bar or bars it was to restrain. Other rules were also given to ensure adequate lateral support of the longitudinal bars.

It is to be noted that for low $\mathrm{P}_{\mathrm{e}} / \mathrm{f}_{\mathrm{C}} \mathrm{A}_{\mathrm{g}}$ ratios, Eqs. 9 to 12 result in lower confining steel contents than the SEAOC recommendations, but that higher confining steel contents than the SEAOC recommendations are required at high axial load levels. Eqs, 9 to 12 were the result(15) of an assessment of moment-curvature analyses of typical column sections $(16,17,18,19)$, which were based on idealised stress-strain curves for concrete confined by either circular or rectangular shaped confining stee. These idealised stress-strain curves were based on a limited number of tests on small specimens but the curves 
used were generally considered to be conservative. The complete stress-strain curve was used in the analyses. That is, the full extent of the "falling branch" of the stress-strain curve after the maximum stress was reached was utilised and hence no arbitrary value for the"ultimate" concrete compressive strain was assumed. Instead, the available curvature ductility factor of the section was judged by assessing the curvature after maximum moment was reached when the section was still carrying a reasonable proportion of the maximum moment. This assessment indicated that the level of confinement provided by Eqs. 9 to 12 should be sufficient to ensure curvature ductility factors well in excess of 5 without the moment capacity decreasing to less than $80 \%$ of the moment capacity at an extreme fibre concrete compressive strain of 0.003 .

\section{(b) Revised Draft}

More recently, experimental results have been obtained $(20,21)$. from tests conducted on a range of near full size reinforced concrete columns using the $10 \mathrm{MN}$ capacity DARTEC servo-hydraulically controlled universal testing machine installed at the University of Canterbury in 1978. The column sections were either $550 \mathrm{~mm}(21.7 \mathrm{in})$ square or $600 \mathrm{~mm}(23.6 \mathrm{in})$ octagonal, with a total height of $3.3 \mathrm{~m}$ $(10.8 \mathrm{ft})$. A range of axial load levels between $0.21 f^{\prime A}$ and $0.70 f^{\prime A}$ was applied and cyclic flexăre imposed to simulate earthquake type loading. The confining steel was designed according to the first draft of the SANZ Concrete Design Code(12) or in one case to the MWD provisions (10). The square columns had transverse steel consisting of overlapping rectangular or octagonal hoops; the octagonal columns had transverse steel consisting of circular spirals. The loading arrangement and the sections of two of the column units tested are shown in Fig. 1. Load-displacement hysteresis loops for these two units tested in the programme, which had been designed according to the draft SANZ code, are shown in Figs. 2 and 3 . In these figures the theoretical ultimate load*decreases with increasing deflection as a result of the $\mathrm{P}-\Delta$ effect. It will be seen that stable hysteresis loops were obtained at displacement ductility factors of 6 for the square column and 8 for the octagonal column. It is of interest that maximum measured core concrete compression strains of 0.026 and 0.080 were obtained from the square and octagonal units tested, respectively. compared with ultimate compressive strains of about 0.01 predicted by the MWD provisions (10). The columns tested could have reached much higher maximum displacement ductility factors than those applied, since at the end of the tests the measured horizontal load-displacement curves were still rising. That is, the maximum load carrying capacity of the columns was not fully reached and the strength was not degrading with further increase in deflection, and this in spite of the fact that strain gauge measurements indicated that yielding of the confining steel had occurred at moderate displacement ductility factors. Thus, the columns tested performed well on the whole. At *Calculated using ACI colum design charts using actual material strengths and with a strength reduction factor $\phi=1$. low axial load levels the concrete was confined satisfactorily, although there was some tendency for spirals to straighten between longitudinal bars. At high axial load levels the columns demonstrated very good behavious, and confirmed the required increase in confining steel with axial load level recommended by the draft SANZ Concrete Design Code. As a result of these test results, and a general reassessment of confining requirements, the confining requirements have been modified as follows in the revised draft of Ref.12.

The potential plastic hinge region for $\mathrm{P}_{e}<\phi 0.3 \mathrm{f}_{\mathrm{C}}^{\prime} \mathrm{A}$ is now recommended as not less than the longer column section dimension in the case of a rectangular section or the diameter in the case of a circular section, or where the moment exceeds 0,8 of the maximum moment at that end of the member. When $\mathrm{P}_{\mathrm{e}}>\phi 0.3 \mathrm{f}_{\mathrm{C}}^{\prime} \mathrm{A}$ the potential plastic hinge region $(20,21)$ is increased to 1.5 times the tests $(20,21)$ hinge region tends to spread along the column, because the flexural strength at the critical section is enhanced by the larger confining steel content. Thus flexural failure could occur in the less heavily confined adjacent regions of column unless the heavy confining steel was spread over a longer length of column.

In potential plastic hinge regions, when spirals or circular hoops are used and either $\mathrm{P}_{e}<\phi 0.7 \mathrm{f}_{\mathrm{C}}^{\prime} \mathrm{A}_{\mathrm{g}}$ or $\mathrm{P}_{\mathrm{e}}<\phi 0.7 \mathrm{P}_{\mathrm{O}}$ ' the volumetric ratio should not be less than

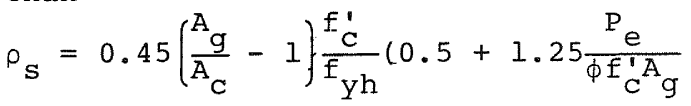

nor

$\rho_{\mathrm{S}}=0.12 \frac{\mathrm{f}_{\mathrm{C}}^{\prime}}{\mathrm{f}_{\mathrm{yh}}}\left(0.5+1.25 \frac{\mathrm{P}_{\mathrm{e}}}{\phi f_{\mathrm{C}^{\prime} \mathrm{A}}^{\mathrm{A}}}\right.$

In potential plastic hinge regions when rectangular hoops, with or without supplementary cross ties, are used and either $\mathrm{P}_{e}<\phi 0.7 \mathrm{f}_{\mathrm{C}} \mathrm{A}_{\mathrm{g}}$ or $\mathrm{P}_{e}<\phi 0.7 \mathrm{P}_{\mathrm{O}^{\prime}}$. the total area of transverse steel within spacing $s_{h}$ should not be less than

$A_{s h}=0.3 s_{h} h^{\prime \prime}\left(\frac{A_{g}}{A_{c}}-1\right) \frac{f_{c}^{\prime}}{f_{y h}}\left(0.5+1.25 \frac{P_{e}}{\phi f_{c}^{\prime} A_{g}}\right.$

nor

$A_{s h}=0.12 s_{h} h^{\prime \prime} \frac{f_{c}^{\prime}}{f_{y h}}\left(0.5+1.25 \frac{P_{e}}{\phi f_{C}^{\prime} A_{g}}\right)$

When the load $P$ has been obtained using a capacity design procedure, the value of the strength reduction factor $\phi$ in all the above equations can be taken as unity.

For both circular and rectangular 


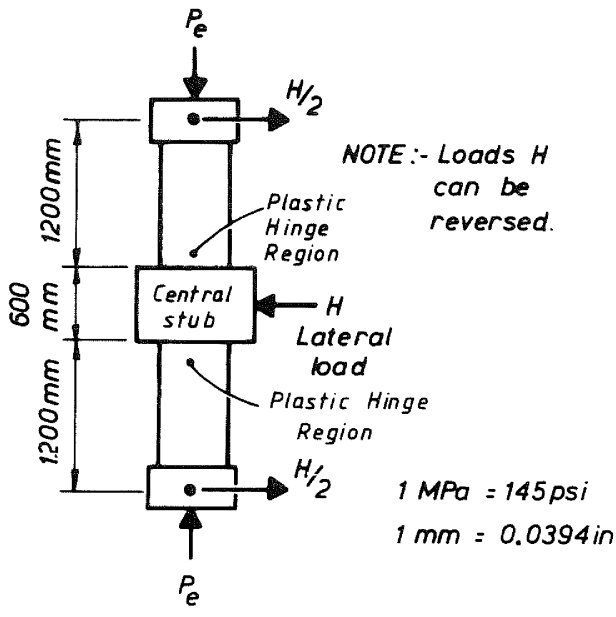

(a) LOADING ARRANGEMENT

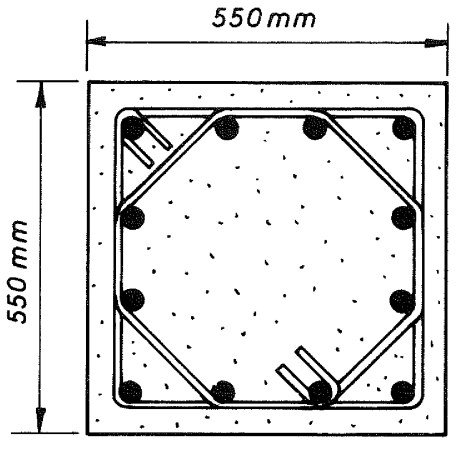

Hoops: $10 \mathrm{~mm}$ dia. a $80 \mathrm{~mm}$ centres.

Long.bars: Twelve $24 \mathrm{~mm}$ dia.

$f_{y h}=297 \mathrm{MPa} \quad f_{y}=375 \mathrm{MPa}$ $f_{c}^{\prime}=23.1 \mathrm{MPa}$

Cover to hoops $=40 \mathrm{~mm}$

$P_{e} / f_{C}^{\prime} A_{g}=0.260$

(D) SECTION OF SOUARE COLUMN UNIT 1 IN PLASTIC HINGE REGION

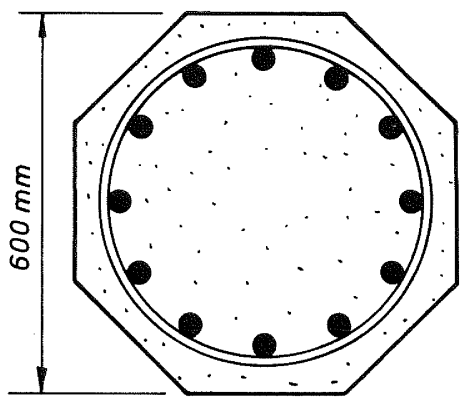

Spiral : $10 \mathrm{~mm}$ dia. $275 \mathrm{~mm}$ centres.

Long. bars: Twelve $24 \mathrm{~mm}$ dia $f_{y h}=300 \mathrm{MPa} \quad f_{y}=303 \mathrm{MPa}$ $f_{c}^{\prime}=28.4 \mathrm{MPa}$

Cover to hoops $=40 \mathrm{~mm}$ $P_{e} / f_{c}^{\prime} A_{g}=0.237$

(c) SECTION OF OCTAGONAL COLUMN UNIT I IN PLASTIC HINGE REGION

Fig. 1 Loading Arrangement and Sections of Two Test Columns $(20,21)$

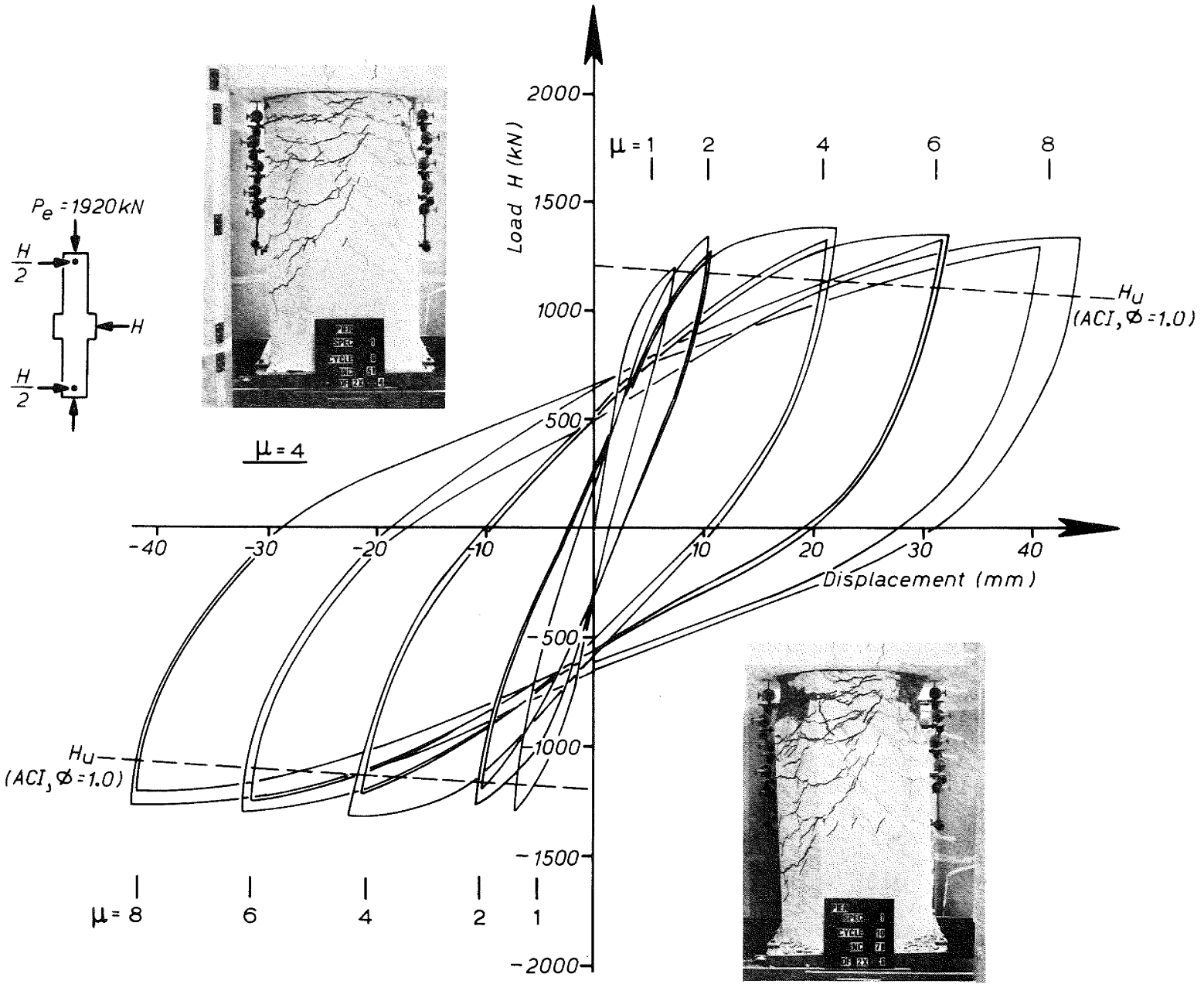

END OF TEST

Fig. 2 Horizontal Load - Horizontal Displacement Loops of Octagonal Column Unit One With $P_{e} / f^{\prime}{ }_{c} A_{g}=0.237$ (20) 
shaped transverse steel the centre to centre spacing in potential plastic hinge zones should not exceed the smaller of one-fifth of the least lateral dimension of the cross section, six longitudinal bar diameters, or $200 \mathrm{~mm}$ (7.9 in). For rectangular hoops the centre to centre spacing between hoop legs or supplementary cross ties across the section, and between longitudinal reinforcing bars, should not exceed the larger of one-third of the section dimension or $200 \mathrm{~mm} \mathrm{(7.9} \mathrm{in).} \mathrm{Also} \mathrm{for} \mathrm{rectangular}$ hoops, each longitudinal bar or bundle of bars should be laterally supported by a corner of a hoop having an included angle of not more than $135^{\circ}$ or by a supplementary cross tie, except that longitudinal bars are exempted from this requirement if either

(1) they lie between two bars supported by the same hoop where the distance between the laterally supported bars does not exceed $200 \mathrm{~mm}$ (7.9 in) between centres, or

(2) they lie within the concrete core of the section centred more than $200 \mathrm{~mm}$ (7.9 in) from the inner face of the hoop.

In additon, for rectangular hoops the yield force in the hoop bar or cross tie should be at least one-sixteenth of the yield force of the longitudinal bar or bars it is to laterally restrain, including the contribution by any bar or bars exempted above from the direct support.

Eqs. 12 to 15 provide a little extra confining steel, particular at low axial load levels, mainly to compensate for the possibility of the actual value of $f^{\prime}$ significantly exceeding the specified value for $f^{\prime}$ (as will generally be the case) and also to better control yielding of the transverse steel. It is expected that confining steel provided in accordance with Eqs. 12 to 15 will be adequate to provide for a curvature ductility factor of $\phi_{1} / \phi$ of at least 20 , which should allow typical bridge piers or building columns in one storey to reach a displacement ductility factor of at least 8 .

The revised draft of DZ310l also allows the amount of confining steel in potential plastic hinge regions to be reduced to one-half of that required by Eqs. 12 to 15 (but without any relaxation of the other provisions) where a design procedure is used to provide the column with sufficient flexural strength to ensure a high degree of protection against plastic hinging. This reduction in confining steel content is not permitted at the bases of columns or piers, or in any storey of a building frame or any bridge pier portal where a column sidesway mechanism will occur with plastic hinges forming in the columns during a severe earthquake.

\section{COMPARISON OF CODE REQUIREMENTS FOR TYPICAI COLUMNS}

The difference between the confinement ratios required by the above codes are illustrated in Figure 4 for a typical $1.5 \mathrm{~m}$ (59 in) diameter circular column confined by a spiral such as would be used in a bridge pier, and in Figure 5 for a typical $700 \mathrm{~mm}$ (27.6 in) square column confined by an arrangement of square and octagonal hoops such as would be used in a building.

(a) Comparison of spiral steel requirements Figure 4

Figure 4 illustrates that the Japanese and CALTRANS quantities of spiral steel are very low, particularly at high axial load levels, and that ACI Committee 343 also recommends only moderate amounts of spiral steel.

The step change in the ACI 318 requirements between Eqs. 2 and 3 has been taken to occur at $\mathrm{P}=0.1 \mathrm{f}^{\prime} \mathrm{A}$ in Figure 4 , which is a reasonable approximation for the specified level of $0.4 \phi \mathrm{P}_{b}$. The SEAOC and ATC recommendations do not permit a reduction in the spiral steel content at low axial load levels. The SANZ (revised draft) quantity shows a linear increase in spiral content with axial load from $50 \%$ of the SEAOC amount at zero axial load to 1.38 times the SEAOC amount at $\mathrm{P}_{\mathrm{B}}$ $=0.7 \mathrm{f}^{\prime} \mathrm{A} \cdot$ It is to be noted that the SEAOC code for the column shown in Figure 4 could be met using a spiral or circular hoops from $20 \mathrm{~mm}$ ( $0.79 \mathrm{in})$ diameter bar at $74 \mathrm{~mm}(2.9 \mathrm{in})$ centre to centre spacing. The longitudinal steel used in this example consisted of twenty one $40 \mathrm{~mm}$ ( 1.57 in) diameter bars. It is obvious that large diameter columns require very large spiral steel bars at close centres for confinement. The linear variation of this quantity of spiral steel with axial load level, as recommended by the draft SANZ code, is more logical than the step function adopted by the ACI 318 approach.

Figure 4 shwos that the MWD approach requires substantially more steel than the other approaches at high axial load levels when the displacement ductility demand is high. For bridge piers the displacement ductility demand for the overall pier structure is normally taken to be $\mu=6$ by the MWD. According to their recommendations, a column with rigid base and monolithic pier/superstructure construction would be designed for $\mu_{\text {pier }}=6$. However, if the foundation is pier flexible, or additional flexibility results from bearings between the pier and superstructure, $\mu_{\text {pier }}$ is required to be greater than 6 . pier This is because the additional flexibility results in an increased yield displacement, while the inelastic displacement will be solely provided by flexural yielding of the columns, resulting in an increased ductility demend on the columns for a given overall structure ductility demand. It is evident that at high axial load levels the MWD requirements can result in extremely high quantities of spiral steel, particularly if the foundations and/or bearings are reasonably flexible. The case of $\mu_{\text {pier }}=8$ illustrated in Figure 4 is for a pier foundation with only very small foundation and/or bearing flexibility. For $\mu_{\text {pier }}=4$, which 
is the usual requirement for building columns, the MWD approach does not result in high spiral contents. For low axial load levels the MWD approach results in uncomfortably small quantities of confining steel, due to the high emphasis of the d/c ratio on $\varepsilon_{\mathrm{Cu}}$ in $\mathrm{Eq} .7$. For example, $\mathrm{Eq} .7$ indicates that $\varepsilon=0.010$ will be available if $\mathrm{c} / \mathrm{d}$ $<0.26^{\mathrm{cu}}$ even if $\rho_{\mathrm{s}}=0$. Clearly Eq. 7 is overly optimistic for low c/d ratios. Note however that the requirements of transverse steel for shear force would mean that the quantity of spiral reinforcement actually present in the column at low axial load levels would exceed that shown in Figure 4 .

\section{(b) Comparison of Rectangular Hoop Steel} Requirements (Figure 5)

Figure 5 illustrates that the Japanese requirements apparently result in very low quantities of hoop steel.

The step change in the ACI 318 requirements has again been taken to occur at $P=0.1 f^{\prime A}$ in Figure 5, which is a reasonable approximation for $0.4 \phi \mathrm{P}$. The SEAOC and ATC recommendations do not permit a reduction in the hoop content at low axial load levels. The SANZ (revised draft) quantity shows a linear increase in hoop content with axial load from 50\% of the SEAOC moment at zero axial load to 1.38 times the SEAOC amount at $\mathrm{P}_{\mathrm{e}}=0.7 \mathrm{f}_{\mathrm{C}}^{\mathrm{A}}$ Using the arrangement of one square hoop $\mathrm{C}$ plus one octagonal hoop per set, shown in the column section in Figure 5, the total effective area of hoop bars per set, A is taken as twice the area of the square hoop leg plus 1.414 (i.e. twice $1 / \sqrt{ } 2$ ) times the area of the octagonal hoop leg. Hence if both hoops are of the same size bar with leg area $\mathrm{A}_{\mathrm{sb}}$ ' the value of $\mathrm{A}_{\text {sh }}$ would be $3.414 \mathrm{~A} \mathrm{sb}^{\circ} \mathrm{Sb}$ The SEAOC code requirements for the column shown in Figure 5 could be met using $16 \mathrm{~mm}$ ( $0.63 \mathrm{in}$ ) diameter square and octagonal hoop bar with the hoop sets placed at $88 \mathrm{~mm}$ (3.46 in) centres. The longitudinal steel used in this example consisted of twelve $32 \mathrm{~mm}$ (1.26 in) diameter bars.

Again, as illustrated in Figure 5, the MWD approach requires substantially more hoop steel than does the other approaches at high axial load levels. low axial load levels only very small quantities of confining steel are again required because of the high emphasis of the $\mathrm{d} / \mathrm{C}$ ratio on $\varepsilon$ in $\mathrm{Eq} .8$. For example, Eq. 8 indicates that $\varepsilon=0.010$ will be available if $\mathrm{c} / \mathrm{d}<0.19^{\mathrm{cu}}$ even if $\rho=0$. However shear would goven the transverse steel quantity in this case. Again there are large differences between the hoop requirements for various $\mu_{\text {pier demands }}$
in Figure 5 .

\section{CONCLUSIONS}

The various overseas and New Zealand code recommendations for transverse confining steel in potential plastic hinge regions of columns and piers in seismic design show vast differences in the required quantities of transverse steel and it is evident that this is still a matter of some controversy.

Recent tests on near full scale reinforced concrete columns containing spiral steel or rectangular hoop steel, under simulated seismic loading, at the University of Canterbury, have shown that the quantities of confining steel recommended in the draft SANZ concrete Design code, with slight modifications mainly to take into account the effect of the possible increase of actual concrete strength over the specified $f^{\prime}$ and to avoid the spread of plastic hinging into less heavily confined regions, will result in available displacement ductility factors for columns of at least 8 .

The provisions for confining steel which have been used by the Ministry of Works and Development for ductile bridge piers appear to be very conservative when axial load levels are high and are in need of revision to avoid the use of excessive quantities of confining steel. This observation is made not only from comparison with the quantity of confining steel required by the draft SANZ Concrete Design code but also in the light of the results of the column tests recently conducted at the University of Canterbury. At low axial load levels the MWD confinement provisions may be unconservative but the requirements of transverse steel for shear will govern in that case and result in a greater quantity of transverse steel being placed.

\section{ACKNOWLEDGEMENT}

This work forms part of a continuing programme of research being conducted at the University of Canterbury into the confining steel requirements of reinforced concrete columns in seismic design. Thanks are due to the University of Canterbury. University Grants Committee, Scientific Research Distribution Committee, Building Research Association, National Roads Board, and the Ministry of Works and Development, for financial grants towards this research, including funding for the DARTEC testing machine.

\section{REFERENCES}

1. "Code of Practice for General Structural Design and Design Loadings for Buildings (NZS 4203:1976)", Standards Association of New Zealand, 1976, 80pp.

2. P.C. Jennings, editor, "Engineering Features of the San Fernando Earthquake, February 9, 1971", Earthquake Engineering Research Laboratory, California Institute of Technology. Pasadena, 1971, 512pp.

3. "Building Code Requirements for Reinforced Concrete (ACI 318-77)" American Concrete Institute, Detroit. $1977,102 \mathrm{pp}$.

4. "Recommended Lateral Force Requirements and Commentary", Seismology Committee Structural Engineers Association of 


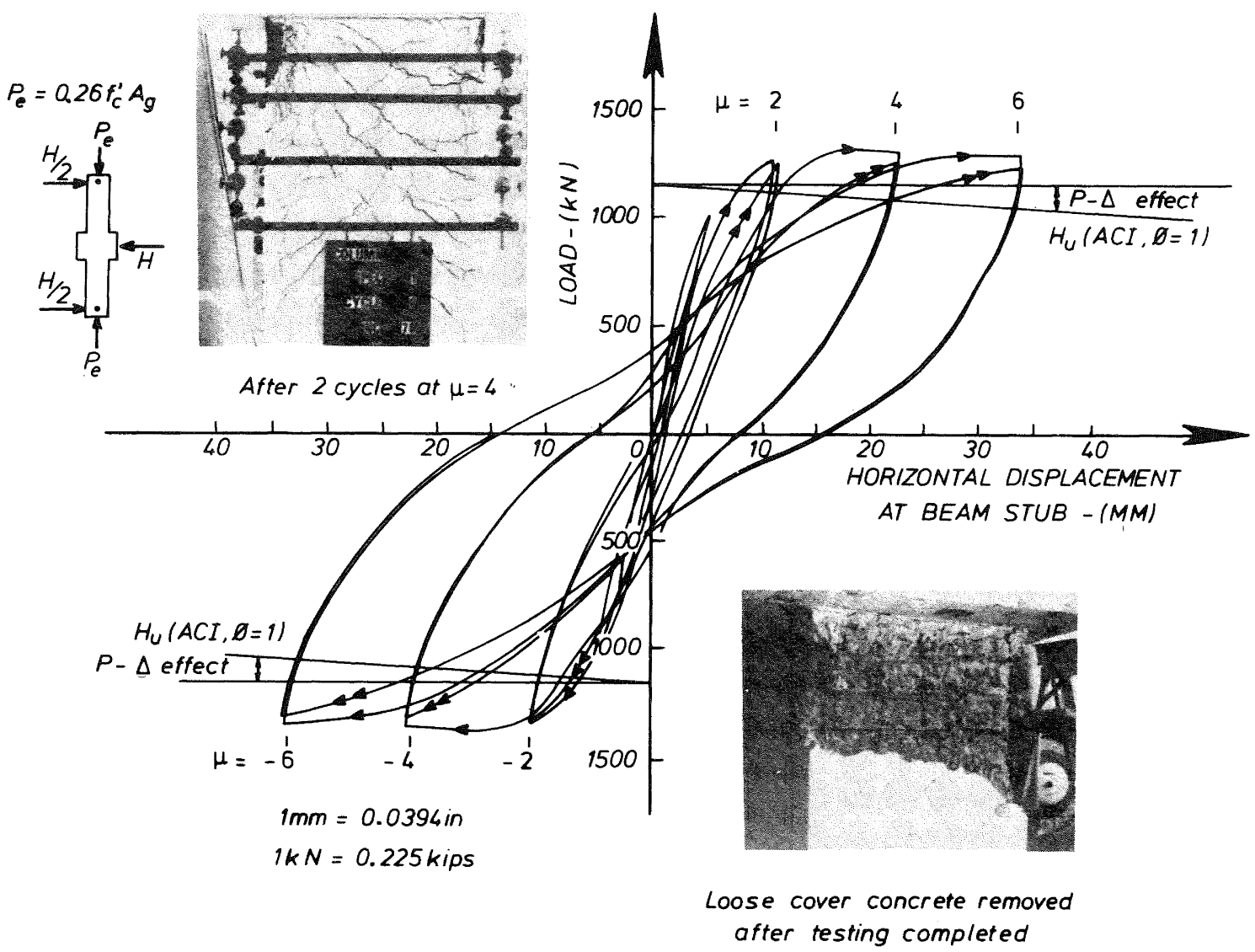

Fig. 3 Horizontal Load - Horizontal Displacement Loops of Square Column Unit One with $P_{e} / f_{c}^{\prime} A_{g}=0.260$ (21)

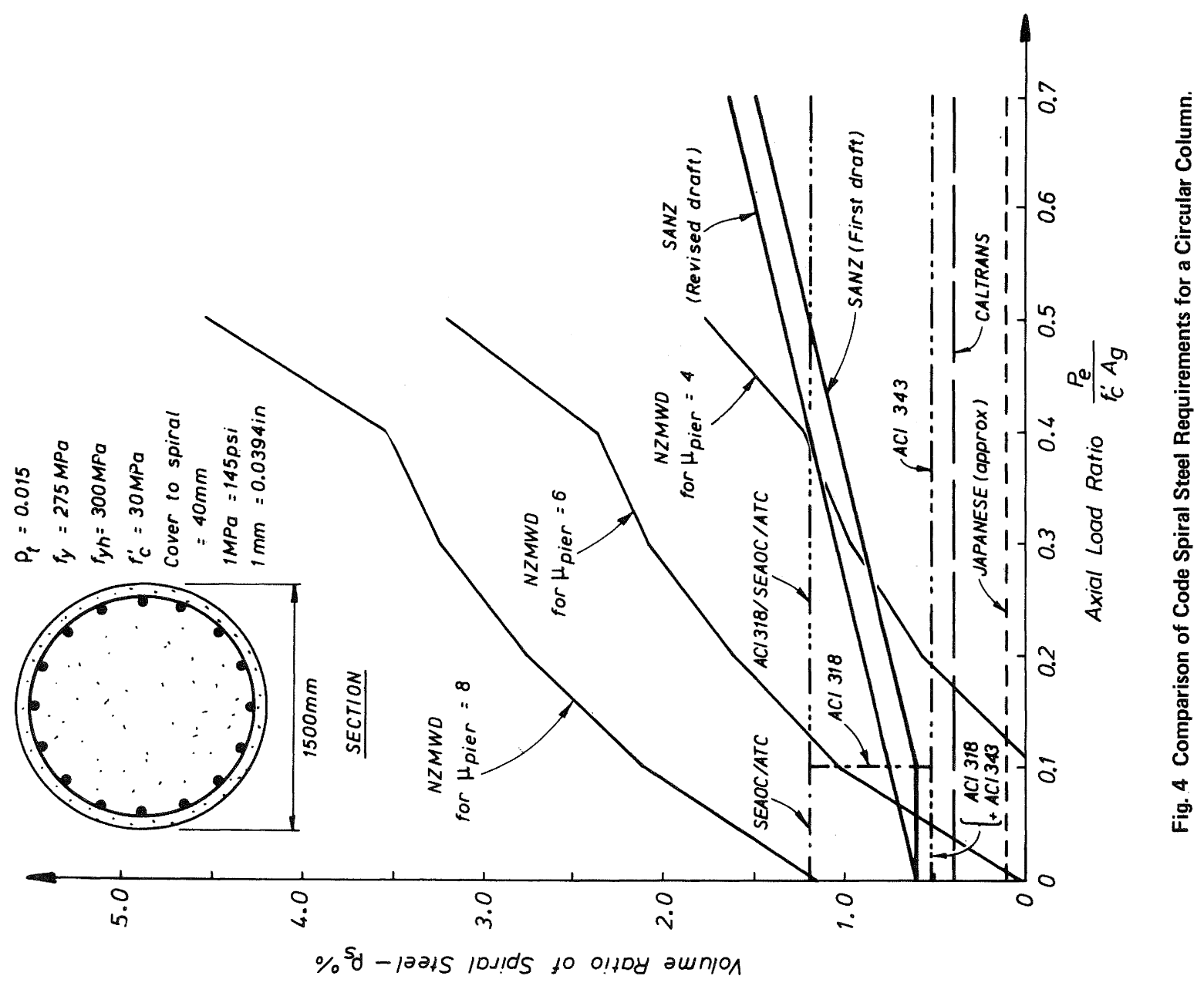


California, 1975, 2lpp plus commentary and appendices.

5. "Tentative Provisions for the Development of Seismic Regulations for Buildings", Applied Technology Council, US Government Printing Office, Washington, 1978, 505pp.

6. "Analysis and Design of Reinforced Concrete Bridge Structures", ACI Committee 343, American Concrete Institute, Detroit, 1977, 116pp.

7. O. Degenkolb, a Private Communication, Department of Transportation, California, October 1979.

8. T. Okubo and T. Iwasaki, "Summary of Experimental and Analytical Seismic Research Recently Performed on Highway Bridges", Proceedings of a Workshop on Seismic Problems Related to Bridges, Applied Technology Council, Palo Alto, California, January 1979.

9. "Design Essentials in Earthquake Resistant Buildings", Architectural Institute of Japan, Tokyo, 1970, 295pp.

10. "Ductility of Bridges with Reinforced Concrete Piers", CDP 810/A, Ministry of Works and Development, April 1975 (plus December 1977 amendment), 109pp.

11. "Highway Design Brief", CDP 701/D, Ministry of Works and Development, September 1978 (plus November 1978 addendum), 52pp.

12. "Draft Code of Practice for the Design of Concrete Structures (DZ 3101)", Standards Association of New Zealand, 1978.

13. "A.L.L. Baker and A.M.N. Amarakone, "Inelastic Hyperstatic Frames Analysis", Proceedings of International Symposium on the Flexural Mechanics of Reinforced Concrete", ASCE-ACI, Miami, Nov. 1964, pp. 85-142.

14. W.L. Chan, "The Ultimate Strength and Deformation of Plastic Hinges in Reinforced Concrete Frameworks", Magazine of Concrete Research, Vol 7 No. 21, Nov. 1955, pp.121-132.

15. R. Park, "Columns Subjected to Flexure and Axial Load", Bulletin of New Zealand National Society for Earthquake Engineering, Vol. 10, No. 2, June 1977, pp. 95-101.

16. R. Park and T. Paulay, "Reinforced Concrete Structures", John Wiley and Sons, New York, 1975, 769pp.

17. R. Park and P.D. Leslie, "Curvature Ductility of Circular Reinforced Concrete columns Confined by the ACI Spiral", 6th Australasian Conference on the Mechanics of structures and Materials, Vol. 1, Christchurch, August 1977, pp.342-349.
18. R. Park and R.A. Sampson, "Ductility of Reinforced Concrete Column Sections in Seismic Design", Journal ACI, Vol. 69, No. 9, Sept. 1972 , pp. 543-551.

19. R. Park and J.A. Norton, "Effects of Confining Reinforcement on the Flexural Ductility of Rectangular Reinforced Concrete Column Sections with High Strength Steel", Symposium on Design and Safety of Reinforced Concrete Compression Members, Reports of Working Commissions, Vol. 16, IABSE, Quebec 1974, pp.267-275.

20. R.T. Potangaroa, M.J.N. Priestley and R. Park, "Ductility of Spirally Reinforced Concrete Columns Under Seismic Loading", Research Report 79-8, Department of Civil Engineering, University of Canterbury, February 1979.

21. W.D. Gill, R. Park and M.J.N. Priestley, "Ductility of Rectangular Reinforced Concrete Columns With Acial Load", Research Report 79-1, Department of Civil Engineering, University of Canterbury, February 1979.

\section{NOTATION}

$A_{C} \quad=$ area of concrete core measured to outside of spiral or hoop

$\mathrm{A}_{\mathrm{g}}=$ gross area of section

$\mathrm{A}_{\mathrm{Sb}}=$ area of rectangular hoop bar (one leg only)

$\mathrm{A}_{\mathrm{sh}}=$ total effective area of hoop bars and supplementary cross ties in the direction under consideration within spacing $\mathrm{s}_{\mathrm{h}}$

$\mathrm{A}_{\mathrm{Sp}}=$ area of spiral or circular hoop bar (one bar)

c = distance from extreme compression fibre to neutral axis

d = distance from extreme compression fibre to centroid of tension reinforcement $(=0.8 \mathrm{~h}$ for circular column)

$\mathrm{d}_{\mathrm{s}}=$ diameter of spiral measured to outside of spiral

$f_{C}^{\prime}=$ specified compressive cylinder strength of concrete

$\mathrm{f}_{\mathrm{Y}} \quad=$ specified yield strength of longitudinal reinforcing steel

$\mathrm{f}_{\mathrm{yh}}=$ specified yield strength of spiral hoop or supplementary cross tie steel

h = diameter of circular column, or depth or width of rectangular column

h" = dimension of concrete core, at right angles to direction of hoop 


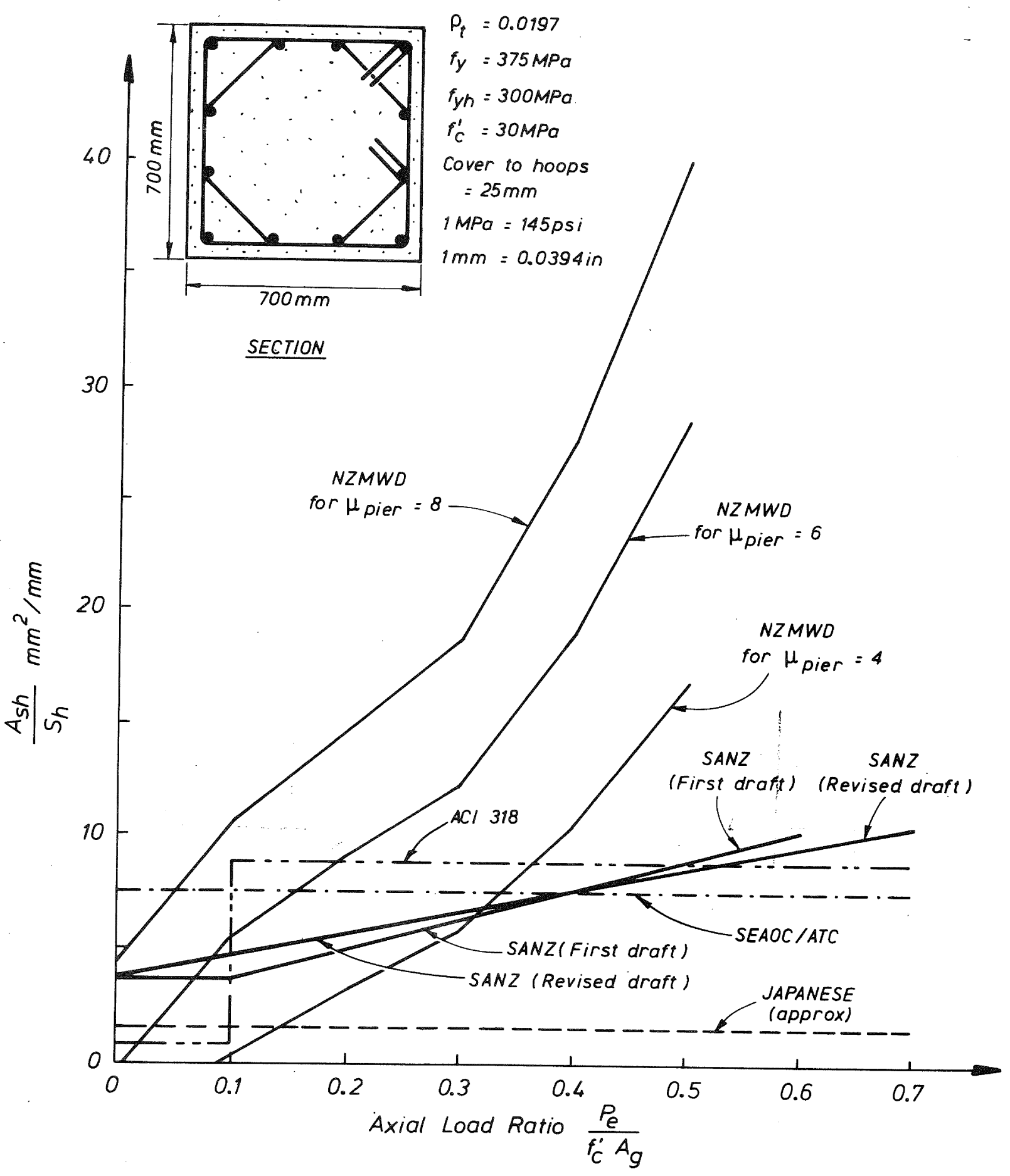

Fig. 5 Comparison of Code Hoop Steel Requirements for a Square Column 


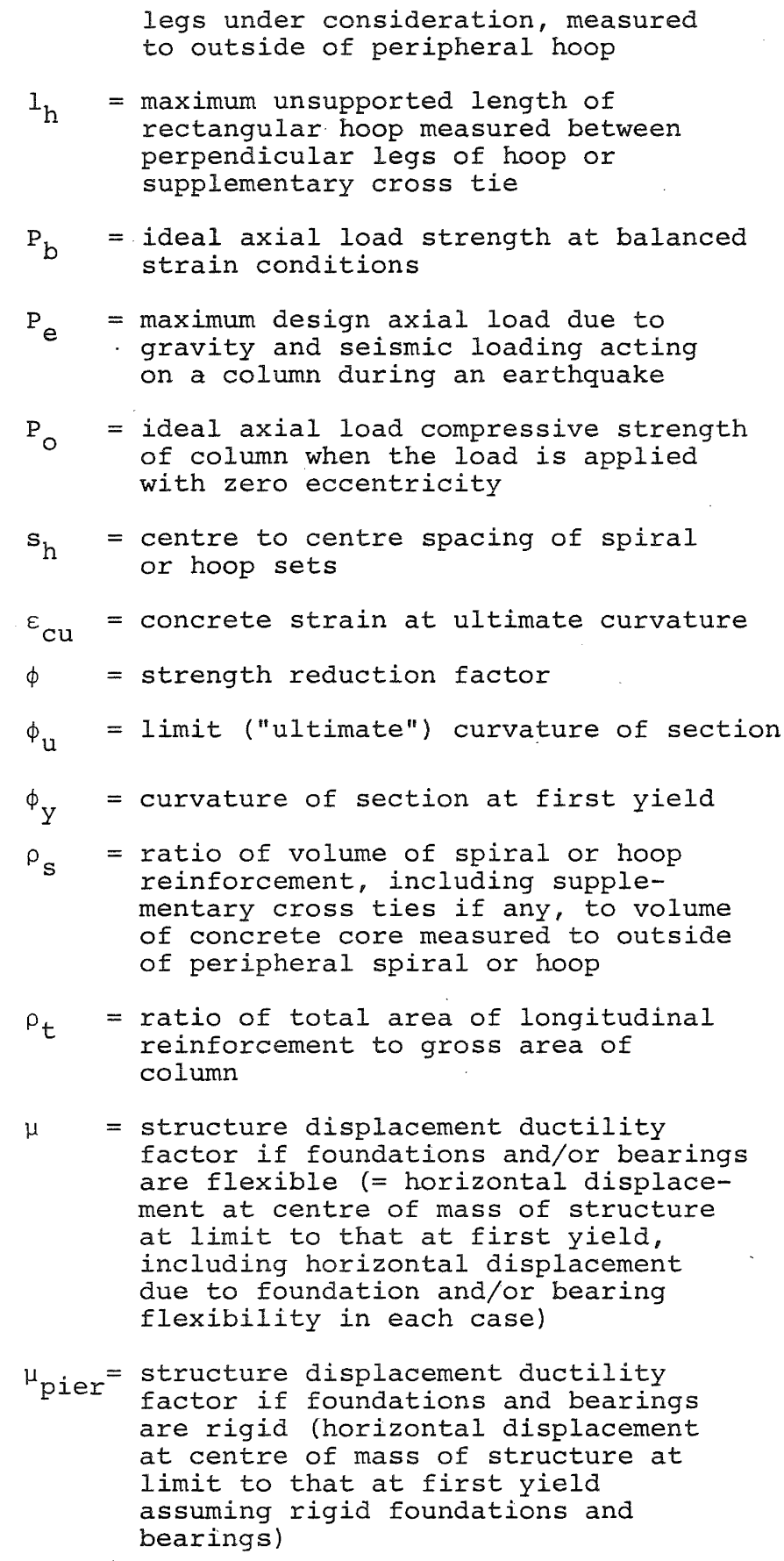

Paper Received 23 November 1979. 